Author affiliations appear at the end of this article.

Submitted October 13, 2011; accepted May 30, 2012; published online ahead of print at www.jco.org on July 16 2012

Written on behalf of the Dutch-Belgian Hemato-Oncology Cooperative Group, and the German Multicenter Myeloma Group.

Supported by the Dutch Cancer Foundation, the German Federal Ministry of Education and Research, and unrestricted Grant No. MMY3003 from Janssen-Cilag-Ortho Biotech. The German Multicenter Myeloma Group was supported by grants from Novartis, Amgen (No. P2004-0060), Chugai, and Roche.

Authors' disclosures of potential conflicts of interest and author contributions are found at the end of this article.

Clinical Trials repository link available on JCO.org.

Corresponding author: Pieter Sonneveld, MD, PhD, Department of Hematology, Erasmus Medical Center, Dr Molewaterplein 40, Room L 407, PO Box 2040, Rotterdam, the Netherlands 3000 CA; e-mail: p.sonneveld@ erasmusmc.nl

(C) 2012 by American Society of Clinica Oncology

0732-183X/12/3024-2946/\$20.00

DOI: $10.1200 / J C O .2011 .39 .6820$

\title{
Bortezomib Induction and Maintenance Treatment in Patients With Newly Diagnosed Multiple Myeloma: Results of the Randomized Phase III HOVON-65/ GMMG-HD4 Trial
}

Pieter Sonneveld, Ingo G.H. Schmidt-Wolf, Bronno van der Holt, Laila el Jarari, Uta Bertsch, Hans Salwender, Sonja Zweegman, Edo Vellenga, Annemiek Broyl, Igor W. Blau, Katja C. Weisel, Shulamiet Wittebol, Gerard M.J. Bos, Marian Stevens-Kroef, Christof Scheid, Michael Pfreundschuh, Dirk Hose, Anna Jauch, Helgi van der Velde, Reinier Raymakers, Martijn R. Schaafsma, Marie-Jose Kersten, Marinus van Marwijk-Kooy, Ulrich Duehrsen, Walter Lindemann, Pierre W. Wijermans, Henk M. Lokhorst, and Hartmut M. Goldschmidt

Processed as a Rapid Communication manuscript. See accompanying editorial on page 2935

$$
\begin{array}{llllllll}
\text { A } & \text { B } & \text { S } & \text { T } & \text { R } & \text { A } & \text { C } & \text { T }
\end{array}
$$

\section{Purpose}

We investigated whether bortezomib during induction and maintenance improves survival in newly diagnosed multiple myeloma (MM).

\section{Patients and Methods}

In all, 827 eligible patients with newly diagnosed symptomatic MM were randomly assigned to receive induction therapy with vincristine, doxorubicin, and dexamethasone (VAD) or bortezomib, doxorubicin, and dexamethasone (PAD) followed by high-dose melphalan and autologous stemcell transplantation. Maintenance consisted of thalidomide $50 \mathrm{mg}$ (VAD) once per day or bortezomib $1.3 \mathrm{mg} / \mathrm{m}^{2}$ (PAD) once every 2 weeks for 2 years. The primary analysis was progression-free survival (PFS) adjusted for International Staging System (ISS) stage.

\section{Results}

Complete response (CR), including near CR, was superior after PAD induction (15\% v 31\%; $P<.001)$ and bortezomib maintenance (34\% $\vee 49 \% ; P<.001)$. After a median follow-up of 41 months, PFS was superior in the PAD arm (median of 28 months $v 35$ months; hazard ratio [HR], $0.75 ; 95 \% \mathrm{Cl}, 0.62$ to $0.90 ; P=.002)$. In multivariate analysis, overall survival (OS) was better in the PAD arm (HR, 0.77; 95\% Cl, 0.60 to 1.00; $P=.049)$. In high-risk patients presenting with increased creatinine more than $2 \mathrm{mg} / \mathrm{dL}$, bortezomib significantly improved PFS from a median of 13 months to 30 months ( $\mathrm{HR}, 0.45 ; 95 \% \mathrm{Cl}, 0.26$ to $0.78 ; P=.004)$ and $\mathrm{OS}$ from a median of 21 months to 54 months ( $\mathrm{HR}, 0.33 ; 95 \% \mathrm{Cl}, 0.16$ to $0.65 ; P<.001)$. A benefit was also observed in patients with deletion 17p13 (median PFS, 12 v 22 months; $\mathrm{HR}, 0.47 ; 95 \% \mathrm{Cl}, 0.26$ to $0.86 ; P=.01$; median OS, 24 months $v$ not reached at 54 months; $\mathrm{HR}, 0.36 ; 95 \% \mathrm{Cl}, 0.18$ to $0.74 ; P=.003$ ).

\section{Conclusion}

Bortezomib during induction and maintenance improves CR and achieves superior PFS and OS.

\section{J Clin Oncol 30:2946-2955. (C) 2012 by American Society of Clinical Oncology}

\section{INTRODUCTION}

High-dose melphalan (HDM) followed by autologous stem-cell transplantation (ASCT) is considered a standard of care for younger patients with multiple myeloma (MM). ${ }^{1-3}$ In the setting of ASCT, high complete response (CR) rates have consistently resulted in prolonged progression-free survival (PFS) and overall survival (OS). ${ }^{4}$ Chemotherapy with vincristine, doxorubicin, and dexamethasone (VAD) has been a standard induction in this setting.,
Proteasome inhibition (bortezomib) and immunomodulatory drugs (thalidomide, lenalidomide) have significant activity in patients with relapsed/refractory $\mathrm{MM}^{7-10}$ Bortezomib combined with melphalan and prednisone achieves $30 \%$ CR in newly diagnosed patients who are not eligible for transplantation. ${ }^{11}$ Likewise, bortezomib combined with dexamethasone (VD) and thalidomide (VTD) results in an improvement of CR and in prolongation of PFS. ${ }^{12,13}$ Although CR predicts for prolonged survival, these schedules have 
not resulted in an improved OS. ${ }^{14,15}$ In high-risk patients with MM presenting with renal failure or with deletion of chromosome $17 \mathrm{p} 13$ and/or $\mathrm{t}(4 ; 14)$, survival remains poor. ${ }^{16-18}$ Consolidation or maintenance therapy following high-dose therapy improves $\mathrm{CR}$ rate and PFS. ${ }^{19}$ Maintenance with thalidomide prolongs PFS but not OS. ${ }^{20-22}$ Lenalidomide maintenance improved PFS in one transplantation study and improved both PFS and OS in another. ${ }^{23,24}$ Bortezomib has been studied as post-ASCT consolidation therapy. ${ }^{13,25,26}$ Use of bortezomib as maintenance therapy has not yet been addressed in younger patients. We report on the results of an open-label randomized phase III trial that evaluated sustained bortezomib treatment during induction and maintenance.

\section{PATIENTS AND METHODS}

\section{Eligibility}

Patients 18 to 65 years of age with newly diagnosed MM Durie-Salmon stage II to III, WHO performance status 0 to 2, or WHO 3 when caused by MM, were eligible. Exclusion criteria were systemic amyloid light chain amyloidosis, nonsecretory MM, neuropathy grade $\geq 2$, active malignancy during the past 5 years with the exception of basal carcinoma of the skin or stage 0 cervical carcinoma, HIV positivity, serum bilirubin $\geq 30 \mu \mathrm{mol} / \mathrm{L}$ or aminotransferases $\geq 2.5 \times$ normal level. Prior corticosteroids were allowed for a maximum of 5 days. Patients with renal impairment were not excluded. Local radiotherapy for painful MM lesions was allowed.

\section{Study Design}

This investigator-sponsored, open-label, randomized phase III trial was designed and performed by the Dutch-Belgian Hemato-Oncology Cooperative Group (HOVON) and the German Multicenter Myeloma Group (GMMG) by using one protocol, data management, and analysis. Patients were randomly assigned 1:1 to VAD induction, ${ }^{5}$ followed by intensification with HDM and ASCT, followed by maintenance therapy with thalidomide (arm A) or bortezomib, doxorubicin, and dexamethasone (PAD), ${ }^{27}$ followed by intensification with HDM and ASCT, followed by maintenance with bortezomib for 2 years (arm B). This design was chosen to evaluate sustained bortezomib treatment (64 administrations) as in VISTA. ${ }^{11}$ Random assignments to VAD or PAD were balanced with use of a biased-coin minimization procedure, with the bias dependent on the average imbalance between numbers of patients already assigned to each treatment arm overall and within the stratification factors of the new patient. ${ }^{28}$ The minimization was initially based on hospital, Durie-Salmon stage ( $2 v 3)$ and lactate dehydrogenase level ( $\leq$ upper limit of normal $v$ greater than upper limit of normal). After the third amendment, the minimization was based on hospital and International Staging System (ISS) stage (I $v$ II $v$ III). Patients were randomly assigned via a Web-based application, Trial Online Process, and the assigned treatment arm was sent immediately via e-mail to local investigators. VAD was administered as three cycles of intravenous (IV) vincristine $0.4 \mathrm{mg}$ per day on days 1 through 4, doxorubicin $9 \mathrm{mg} / \mathrm{m}^{2}$ per day on days 1 through 4 , and oral dexamethasone $40 \mathrm{mg}$ per day on days 1 through 4,9 to 12 , and 17 to 20, every 28 days. PAD induction included three cycles of IV bortezomib $1.3 \mathrm{mg} / \mathrm{m}^{2}$ per day on days 1 , 4,8 , and 11; doxorubicin $9 \mathrm{mg} / \mathrm{m}^{2}$ per day on days 1 through 4 , and oral dexamethasone $40 \mathrm{mg}$ per day on days 1 through 4, 9 to 12 , and 17 to 20, every 28 days. Stem-cell collection was performed 4 to 6 weeks after induction. ${ }^{20}$ HDM $200 \mathrm{mg} / \mathrm{m}^{2}$ and ASCT were administered as described. ${ }^{20}$ Per protocol, one or two cycles of HDM were planned, according to HOVON (single) and GMMG (double) standards, respectively. Patients randomly assigned to VAD received maintenance with thalidomide $50 \mathrm{mg}$ per day for 2 years, starting at 4 weeks after HDM. Patients randomly assigned to PAD received maintenance with IV bortezomib $1.3 \mathrm{mg} / \mathrm{m}^{2}$ once every 2 weeks for 2 years $(\mathrm{n}=52)$ starting at 4 weeks after HDM. Patients with an HLA-identical sibling could proceed to nonmyeloablative allogeneic stem-cell transplantation (alloSCT) after HDM. Maintenance was not given after alloSCT. Supportive care was given as described in the Appendix (online only).

\begin{tabular}{|c|c|c|c|c|}
\hline \multirow[b]{2}{*}{ Characteristic } & \multicolumn{2}{|c|}{$\begin{array}{c}\text { VAD } \\
(n=414)\end{array}$} & \multicolumn{2}{|c|}{$\begin{array}{c}\text { PAD } \\
(n=413)\end{array}$} \\
\hline & No. & $\%$ & No. & $\%$ \\
\hline \multicolumn{5}{|l|}{ Study group } \\
\hline HOVON & 213 & 51 & 219 & 53 \\
\hline GMMG & 201 & 49 & 194 & 47 \\
\hline \multicolumn{5}{|l|}{ Age, years } \\
\hline Median & \multicolumn{2}{|c|}{57} & \multicolumn{2}{|c|}{57} \\
\hline Range & \multicolumn{2}{|c|}{$25-65$} & \multicolumn{2}{|c|}{$31-65$} \\
\hline Male sex & 247 & 60 & 253 & 61 \\
\hline \multicolumn{5}{|l|}{ WHO performance stage } \\
\hline 0 & 183 & 44 & 193 & 47 \\
\hline 1 & 173 & 42 & 170 & 41 \\
\hline 2 & 47 & 11 & 31 & 8 \\
\hline 3 & 8 & 2 & 15 & 4 \\
\hline Unknown & 3 & 1 & 4 & 1 \\
\hline \multicolumn{5}{|l|}{ ISS stage } \\
\hline I & 144 & 35 & 144 & 35 \\
\hline$\|$ & 124 & 30 & 150 & 36 \\
\hline III & 107 & 26 & 81 & 20 \\
\hline Unknown & 39 & 9 & 38 & 9 \\
\hline \multicolumn{5}{|l|}{ M-protein isotype } \\
\hline $\lg A$ & 97 & 23 & 92 & 22 \\
\hline $\lg G$ & 234 & 57 & 251 & 61 \\
\hline $\lg D$ & 3 & 1 & 5 & 1 \\
\hline LCD & 78 & 19 & 63 & 15 \\
\hline Other & 2 & 0 & 2 & 0 \\
\hline \multicolumn{5}{|l|}{ M-protein light chain } \\
\hline Kappa & 278 & 67 & 277 & 67 \\
\hline Lambda & 136 & 33 & 135 & 33 \\
\hline Unknown & 0 & 0 & 1 & 0 \\
\hline \multicolumn{5}{|l|}{ Creatinine, $\mathrm{mg} / \mathrm{dL}$} \\
\hline$\leq 2$ & 368 & 89 & 376 & 91 \\
\hline$>2$ & 45 & 11 & 36 & 9 \\
\hline Unknown & 1 & 0 & 1 & 0 \\
\hline \multicolumn{5}{|l|}{ No. of skeletal lesions } \\
\hline 0 & 96 & 23 & 102 & 25 \\
\hline $1-2$ & 42 & 10 & 44 & 11 \\
\hline$\geq 3$ & 264 & 64 & 255 & 62 \\
\hline Unknown & 12 & 3 & 12 & 3 \\
\hline \multicolumn{5}{|l|}{ Serum LDH } \\
\hline$\leq$ ULN & 331 & 80 & 329 & 80 \\
\hline$>$ ULN & 72 & 17 & 72 & 17 \\
\hline Unknown & 11 & 3 & 12 & 3 \\
\hline \multicolumn{5}{|l|}{$\begin{array}{l}\text { Genetic abnormalities } \\
\text { del(13q) }\end{array}$} \\
\hline Done & 372 & 90 & 361 & 88 \\
\hline Positive, $\%$ of done & 164 & 44 & 148 & 41 \\
\hline \multicolumn{5}{|l|}{$\mathrm{t}(4 ; 14)$} \\
\hline Done & 262 & 63 & 250 & 61 \\
\hline Positive, $\%$ of done & 35 & 13 & 35 & 14 \\
\hline del(17p13) & & & & \\
\hline Done & 313 & 76 & 289 & 70 \\
\hline Positive, $\%$ of done & 40 & 13 & 25 & 9 \\
\hline Median $\beta_{2}$-microglobulin, mg/L & & & & \\
\hline Median hemoglobin, mmol/L & & & & \\
\hline Median calcium, mmol/L & & & & \\
\hline Median No. of bone marrow plasma cells & & & & \\
\hline $\begin{array}{l}\text { Abbreviations: GMMG, German Multice } \\
\text { Dutch-Belgian Hemato-Oncology Coopera } \\
\text { ISS, International Staging System; LCD, } \\
\text { lactate dehydrogenase; PAD, bortezomib, d } \\
\text { upper limit of normal; VAD, vincristine, dox }\end{array}$ & $\begin{array}{l}\text { Mye } \\
\text { Grou } \\
\text { t-chair } \\
\text { rubicir } \\
\text { bicin, }\end{array}$ & $\begin{array}{l}\text { na } \\
\text { lg, i } \\
\text { iseas } \\
\text { exam } \\
\text { rame }\end{array}$ & $\begin{array}{l}\text { up; H } \\
\text { munog } \\
\text { LDH, } \\
\text { hason } \\
\text { asone. }\end{array}$ & \\
\hline
\end{tabular}




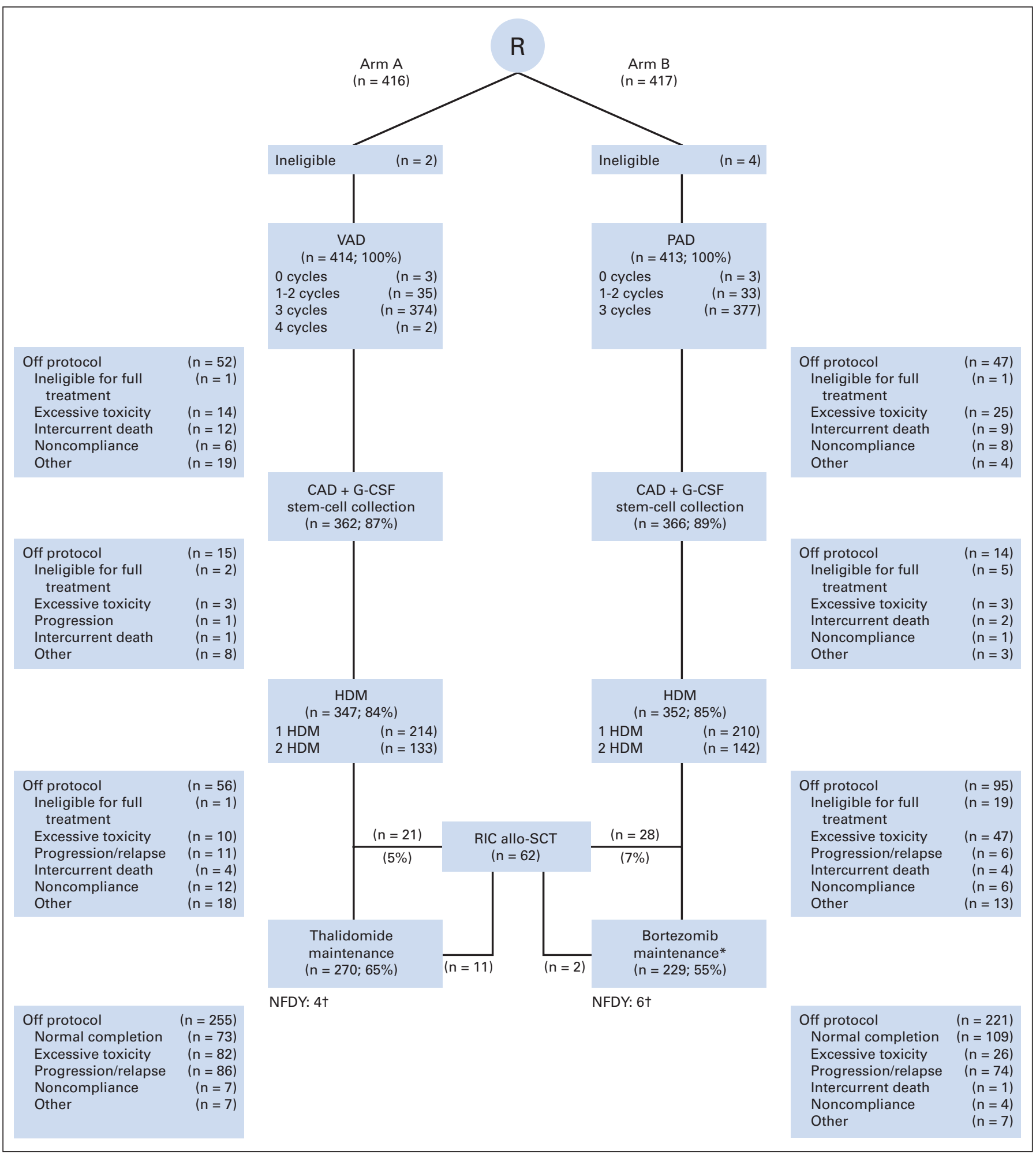

Fig 1. CONSORT diagram of 827 adult patients with multiple myeloma (MM) in the Dutch-Belgian Hemato-Oncology Group 65/German Multicenter Myeloma Group HD4 (HOVON-65/GMMG-HD4) study by treatment arm. allo-SCT, allogeneic stem-cell transplantation; CAD, cyclophosphamide, doxorubicin, dexamethasone; G-CSF, granulocyte colony-stimulating factor; HDM, high-dose melphalan; PAD, bortezomib, doxorubicin, and dexamethasone; R, random assignment; RIC, reduced intensity conditioning; VAD, vincristine, doxorubicin, and dexamethasone. $\left(^{*}\right)$ Including one patient with thalidomide plus bortezomib and one patient with thalidomide only. ( $\dagger$ ) NFDY, no further data yet. 


\begin{tabular}{|c|c|c|c|c|c|}
\hline \multirow[b]{2}{*}{ Response } & \multicolumn{2}{|c|}{$\operatorname{VAD}(n=414)$} & \multicolumn{2}{|c|}{$\operatorname{PAD}(n=413)$} & \multirow[b]{2}{*}{$P$} \\
\hline & No. & $\%$ & No. & $\%$ & \\
\hline \multicolumn{6}{|l|}{ Response after induction } \\
\hline $\mathrm{CR}$ & 7 & 2 & 29 & 7 & $<.001$ \\
\hline$\geq \mathrm{nCR}$ & 20 & 5 & 46 & 11 & $<.001$ \\
\hline$\geq$ VGPR & 59 & 14 & 174 & 42 & $<.001$ \\
\hline$\geq P R$ & 222 & 54 & 322 & 78 & $<.001$ \\
\hline \multicolumn{6}{|l|}{ Response after HDM } \\
\hline $\mathrm{CR}$ & 37 & 9 & 85 & 21 & $<.001$ \\
\hline$\geq \mathrm{nCR}$ & 62 & 15 & 127 & 31 & $<.001$ \\
\hline$\geq$ VGPR & 150 & 36 & 254 & 62 & $<.001$ \\
\hline$\geq P R$ & 312 & 75 & 363 & 88 & $<.001$ \\
\hline \multicolumn{6}{|l|}{ Response overall } \\
\hline $\mathrm{CR}$ & 99 & 24 & 147 & 36 & $<.001$ \\
\hline$\geq \mathrm{nCR}$ & 140 & 34 & 201 & 49 & $<.001$ \\
\hline$\geq$ VGPR & 230 & 56 & 312 & 76 & $<.001$ \\
\hline$\geq P R$ & 343 & 83 & 373 & 90 & .002 \\
\hline \multicolumn{6}{|c|}{ Response upgrade during maintenance } \\
\hline Any response upgrade & 99 & 24 & 93 & 23 & .64 \\
\hline$<\mathrm{CR} \rightarrow \mathrm{CR}$ & 45 & 11 & 48 & 12 & .73 \\
\hline$<\mathrm{nCR} \rightarrow \mathrm{nCR}$ & 16 & 4 & 23 & 6 & .25 \\
\hline$<\mathrm{VGPR} \rightarrow \mathrm{VGPR}$ & 27 & 7 & 20 & 5 & .30 \\
\hline$<\mathrm{PR} \rightarrow \mathrm{PR}$ & 11 & 3 & 2 & 0 & .008 \\
\hline ISS stage I & \multicolumn{2}{|r|}{$(n=144)$} & \multicolumn{2}{|c|}{$(n=144)$} & \\
\hline$C R$ & 37 & 26 & 59 & 41 & .006 \\
\hline$\geq \mathrm{nCR}$ & 58 & 40 & 78 & 54 & .018 \\
\hline$\geq$ VGPR & 94 & 65 & 115 & 80 & .005 \\
\hline$\geq P R$ & 130 & 90 & 132 & 92 & .68 \\
\hline ISS stage II & & $(n=124)$ & & & \\
\hline $\mathrm{CR}$ & 29 & 23 & 51 & 34 & .05 \\
\hline$\geq \mathrm{nCR}$ & 35 & 28 & 70 & 47 & .002 \\
\hline$\geq$ VGPR & 59 & 48 & 109 & 73 & $<.001$ \\
\hline$\geq \mathrm{PR}$ & 100 & 81 & 134 & 89 & .04 \\
\hline ISS stage III & & $(n=107)$ & & & \\
\hline$C R$ & 24 & 22 & 26 & 32 & .14 \\
\hline$\geq \mathrm{nCR}$ & 35 & 33 & 35 & 43 & .14 \\
\hline$\geq$ VGPR & 57 & 53 & 56 & 69 & .03 \\
\hline$\geq P R$ & 82 & 77 & 70 & 86 & .09 \\
\hline ISS stage unknown & & $(n=39)$ & & & \\
\hline $\mathrm{CR}$ & 9 & 23 & 11 & 29 & .56 \\
\hline$\geq \mathrm{nCR}$ & 12 & 31 & 18 & 47 & .13 \\
\hline$\geq$ VGPR & 20 & 51 & 32 & 84 & .002 \\
\hline$\geq P R$ & 31 & 79 & 37 & 97 & .01 \\
\hline$\beta_{2}$-microglobulin $>3 \mathrm{mg} / \mathrm{L}$ & & $(n=220)$ & & & \\
\hline$C R$ & 50 & 23 & 77 & 35 & .006 \\
\hline$\geq \mathrm{nCR}$ & 67 & 30 & 103 & 46 & $<.001$ \\
\hline$\geq$ VGPR & 114 & 52 & 163 & 73 & $<.001$ \\
\hline$\geq P R$ & 173 & 79 & 198 & 89 & .004 \\
\hline Creatinine $>2 \mathrm{mg} / \mathrm{dL}$ & & $(n=45)$ & & & \\
\hline $\mathrm{CR}$ & 6 & 13 & 13 & 36 & .02 \\
\hline$\geq \mathrm{nCR}$ & 12 & 27 & 19 & 53 & .02 \\
\hline$\geq$ VGPR & 18 & 40 & 28 & 78 & $<.001$ \\
\hline$\geq P R$ & 29 & 64 & 31 & 86 & .02 \\
\hline \multicolumn{6}{|l|}{ Genetic abnormalities } \\
\hline$\geq \mathrm{nCR}$ & 53 & 32 & 76 & 51 & $<.001$ \\
\hline$\geq$ VGPR & 88 & 54 & 124 & 84 & $<.001$ \\
\hline$t(4 ; 14)$ & & $(n=35)$ & & & \\
\hline$\geq \mathrm{nCR}$ & 11 & 31 & 20 & 57 & .03 \\
\hline$\geq$ VGPR & 20 & 57 & 30 & 86 & .007 \\
\hline del(17p13) & & $(n=40)$ & & & \\
\hline$\geq \mathrm{nCR}$ & 8 & 20 & 13 & 52 & .008 \\
\hline$\geq$ VGPR & 17 & 43 & 18 & 72 & .02 \\
\hline
\end{tabular}


This study was approved by the ethics committees of the Erasmus University Medical Center, the University of Heidelberg, and the participating sites. All patients gave written informed consent, and the trial was conducted according to the European Clinical Trial Directive 2005 and the Declaration of Helsinki.

\section{Response Assessments and End Points}

Clinical characteristics were recorded at diagnosis. Cytogenetic studies were performed as described in the Appendix. ${ }^{29}$ Evaluation of response was performed according to modified European Group for Blood and Marrow Transplantation (EBMT) criteria. ${ }^{30}$ Near CR (nCR) and very good partial response (VGPR) were implemented as in the International Myeloma Working Group (IMWG) response criteria. ${ }^{31} \mathrm{nCR}$ was defined as $\mathrm{CR}$ with positive or missing immunofixation, ${ }^{8}$ and VGPR was defined as more than $90 \%$ reduction of serum M-protein and urine light chain less than $100 \mathrm{mg} / 24$ hours. $\mathrm{CR}$ required negative serum/urine immunofixation and bone marrow morphology evaluation. Responses were assessed after induction, after first and second transplantation, at 2-month intervals during maintenance, and until progression. PFS was calculated from random assignment until progression, relapse, or death, whichever came first. Patients who received a nonmyeloablative alloSCT, however, were censored at the date of alloSCT. PFS without censoring of alloSCT patients has been denoted as $\mathrm{PFS}_{\mathrm{A}}$. OS was measured from random assignment until death from any cause. Patients alive at the date of last contact were censored.

\section{Statistical Analysis}

The primary objective of the study was to compare PFS between the treatment arms. The expected PFS in the VAD arm was $50 \%$ at 3 years. To detect a hazard ratio (HR) of 0.74 with a power of $80 \%$, which corresponds to an increase of 3-year PFS from 50\% to 60\% (two-sided significance level of $\alpha=.049$, because of one planned interim analysis at a significance level of $\alpha=.001$ ), and assuming 3 years of accrual, additional follow-up time of 2 years, and 10\% alloSCT, 800 patients had to be randomly assigned and 356 events had to be observed. All analyses were performed by intention-to-treat, and the primary analysis was done with a multivariate Cox regression that included adjustment for ISS stage.

Secondary end points included response, $\mathrm{PFS}_{\mathrm{A}}$ (without censoring pa-

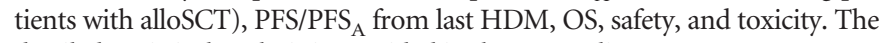
detailed statistical analysis is provided in the Appendix.

\section{RESULTS}

\section{Patients}

In all, 833 patients were recruited from May 2005 to May 2008. Two (VAD) and four (PAD) ineligible patients were excluded from analyses because they had nonsecreting myeloma $(\mathrm{n}=4)$, misdiagnosis, or prior treatment $(n=2)$. Thus, 827 patients were randomly assigned to $\operatorname{VAD}(\mathrm{n}=414)$ or PAD $(\mathrm{n}=413)$. Patient characteristics at inclusion did not differ between the two groups (Table 1). Eightyone patients $(10 \%)$ with impaired renal function (Durie -Salmon stage $\mathrm{B}$; serum creatinine more than $2 \mathrm{mg} / \mathrm{dL}$ ) were included.

\section{Adherence to Treatment}

The flow of patients through the protocol is shown in Figure 1. Intensification with first HDM was achieved in $84 \%$ of patients, and $69 \%$ of GMMG patients completed a second HDM. Of those patients in the VAD arm, 77 (22\%) of 347 went off protocol after HDM because of alloSCT $(n=21 ; 6 \%)$, persisting toxicity $(n=11 ; 3 \%)$, or other reasons ( $\mathrm{n}=45 ; 13 \%)$, although 270 patients $(78 \%)$ started maintenance treatment. In the PAD arm, 123 (35\%) of 352 patients went off protocol because of alloSCT $(n=28 ; 8 \%)$, persisting toxicity ( $\mathrm{n}=47 ; 13 \%$, mainly polyneuropathy), or other $(\mathrm{n}=48 ; 14 \%)$, and $229(65 \%)$ started maintenance with bortezomib $(P=.004$; Fig 1). Persisting toxicity was an exclusion criterium for starting maintenance and, within the group of patients who went off protocol (excluding alloSCT patients), this was observed in 11 (14\%) of 77 in the VAD arm versus $47(38 \%)$ of 123 in the PAD arm $(P<.001)$. Normal completion of maintenance was achieved in $73(27 \%)$ of 270 patients (VAD) and $109(47 \%)$ of 229 patients (PAD; Appendix Table A1, online only).

\section{Response}

Overall response is given in Table 2. The CR rate was $24 \%$ in patients who were randomly assigned to VAD and $36 \%$ in patients randomly assigned to $\mathrm{PAD}(P<.001)$. Overall nCR plus $\mathrm{CR}$ rates were $34 \%$ versus $49 \%$, respectively $(P<.001)$. After induction, all responses (ie, at least partial response [PR], at least VGPR, and at least $\mathrm{nCR}$ ) were superior in the PAD arm. Response rates increased from induction to significantly higher than equal to or greater than VGPR and equal to or greater than nCR following HDM/ASCT in the PAD arm. The response rate for nCR plus CR after transplantation was $15 \%$ (VAD) versus 31\% (PAD), respectively $(P<.001)$. During maintenance, an upgrade of response (from less than PR to PR, less than VGPR to VGPR, less than nCR to nCR, or less than CR to CR) was

\begin{tabular}{|c|c|c|c|c|c|c|}
\hline \multirow[b]{2}{*}{ Risk Factor } & \multicolumn{3}{|c|}{ PFS } & \multicolumn{3}{|c|}{ OS } \\
\hline & $\mathrm{HR}$ & $95 \% \mathrm{Cl}$ & $P$ & $\mathrm{HR}$ & $95 \% \mathrm{Cl}$ & $P$ \\
\hline PAD treatment arm & 0.74 & 0.62 to 0.89 & .001 & 0.77 & 0.60 to 1.00 & .049 \\
\hline Age (years) & 1.00 & 0.99 to 1.02 & .53 & 1.00 & 0.99 to 1.02 & .61 \\
\hline Female sex & 0.85 & 0.70 to 1.02 & .08 & 0.85 & 0.65 to 1.11 & .24 \\
\hline ISS stage (I, II, III) & 1.24 & 1.09 to 1.41 & .001 & 1.45 & 1.21 to 1.74 & $<.001$ \\
\hline WHO PS $(0,1,2,3)$ & 1.25 & 1.11 to 1.42 & $<.001$ & 1.52 & 1.29 to 1.79 & $<.001$ \\
\hline $\lg A^{*}$ & 1.59 & 1.19 to 2.13 & .002 & 1.81 & 1.19 to 2.75 & .006 \\
\hline $\operatorname{lgG} \dagger$ & 1.33 & 1.03 to 1.72 & .03 & 1.54 & 1.07 to 2.23 & .02 \\
\hline Durie-Salmon stage 3 & 1.02 & 0.79 to 1.33 & .86 & 1.02 & 0.70 to 1.48 & .93 \\
\hline LDH $>$ ULN & 1.28 & 1.01 to 1.63 & .04 & 1.68 & 1.24 to 2.29 & .001 \\
\hline $\operatorname{del}(13 / 13 q 14)$ & 1.39 & 1.13 to 1.70 & .002 & 1.70 & 1.29 to 2.23 & $<.001$ \\
\hline SG (double HDM policy) & 0.87 & 0.73 to 1.05 & .15 & 0.75 & 0.57 to 0.97 & .03 \\
\hline
\end{tabular}


observed in $24 \%$ of patients in the VAD arm and $23 \%$ in the PAD arm (Table 2). The median time to any response upgrade after start of maintenance was 6 months for VAD (range, 1 to 35 months) versus 7 months for PAD (range, 1 to 57 months).

\section{PFS and OS}

The median PFS was 28 months for the VAD arm and 35 months for the PAD arm. Patients who were assigned to PAD had a significantly better PFS (HR, $0.75 ; 95 \%$ CI, 0.62 to $0.90 ; P=.002)$ when adjusted for ISS (primary analysis) and also in the multivariate analysis (HR, 0.74; 95\% CI, 0.62 to $0.89 ; P=.001$; Table 3, and Fig 2A). The median $\mathrm{PFS}_{\mathrm{A}}$ (ie, without censoring of alloSCT) was 28 months (VAD) versus 34 months (PAD), respectively (Fig 2B).

Median OS was not reached at 66 months in either arm, with 5 -year OS of 55\% (VAD) versus 61\% (PAD; Fig 2C). When OS was adjusted for ISS, an HR of 0.81 (95\% CI, 0.63 to $1.05 ; P=.11$ ) was noted, but OS difference reached statistical significance in the multivariate analysis ( $\mathrm{HR}, 0.77 ; 95 \% \mathrm{CI}, 0.60$ to $1.00 ; P=.049$ ). It should be noted that both HRs and 95\% CIs are quite similar. OS also differed between study groups, with the GMMG patients having a better OS (HR, $0.75 ; 95 \%$ CI, 0.57 to $0.97 ; P=.03$ ). An analysis of PFS calculated from the time of last HDM $(n=645)$ showed a significant difference in favor of the PAD arm, with a median of 26 months versus 31 months (Appendix Fig A1A, online only). This indicates that although post-transplantation bortezomib and thalidomide both achieved response upgrades, bortezomib contributed more to improvement of PFS. In a landmark analysis starting at 12 months after random assignment for 585 patients (283, VAD; 302, PAD) who had received HDM/ASCT and were still without progression, PFS $(P=.04$; Appendix Fig A1B) and OS $(P=.05$; Appendix Fig A1C) were improved in the PAD arm.

\section{Safety}

The safety profiles and most common toxicities are listed in Appendix Table A2 (online only). Peripheral neuropathy (PNP) occurred more often in the PAD arm. Within the first year of treatment, PNP grades 2 to 4 were reported in 18\% (VAD) and 40\% (PAD) of patients (HR, $1.50 ; 95 \% \mathrm{CI}, 1.20$ to $1.88 ; P<.001)$. In addition, newly developed grade 3 to 4 PNP occurred in $8 \%$ of patients during thalidomide maintenance and $5 \%$ of patients during bortezomib maintenance. In $82(30 \%)$ of 270 patients receiving thalidomide maintenance, toxicity was a reason to stop treatment prematurely compared with 26 (11\%) of 229 patients receiving bortezomib maintenance $(P<.001)$. The most frequent toxicities occurring during maintenance are listed in Appendix Table A2. Progression or relapse were reasons to stop maintenance prematurely in $86(32 \%)$ of 270 patients during thalidomide treatment versus 74 (32\%) of 229 patients during bortezomib treatment.

\section{Secondary Analyses}

To explore a possible differential effect of bortezomib treatment in any of the subgroups, the effect of treatment was estimated separately by HRs for PFS and OS, with associated 95\% CIs combined with tests for interaction. The interactions were especially significant for serum creatinine, fluorescent in situ hybridization (FISH) del(13q14) and FISH del(17p13). Results of these subgroups are presented in detail in Neben et al. ${ }^{32}$ Bortezomib resulted in a superior outcome in patients with increased serum creatinine. In these patients, both median PFS (13 v 30 months; HR, 0.45; 95\% CI, 0.26 to $0.78 ; P=.004$ )

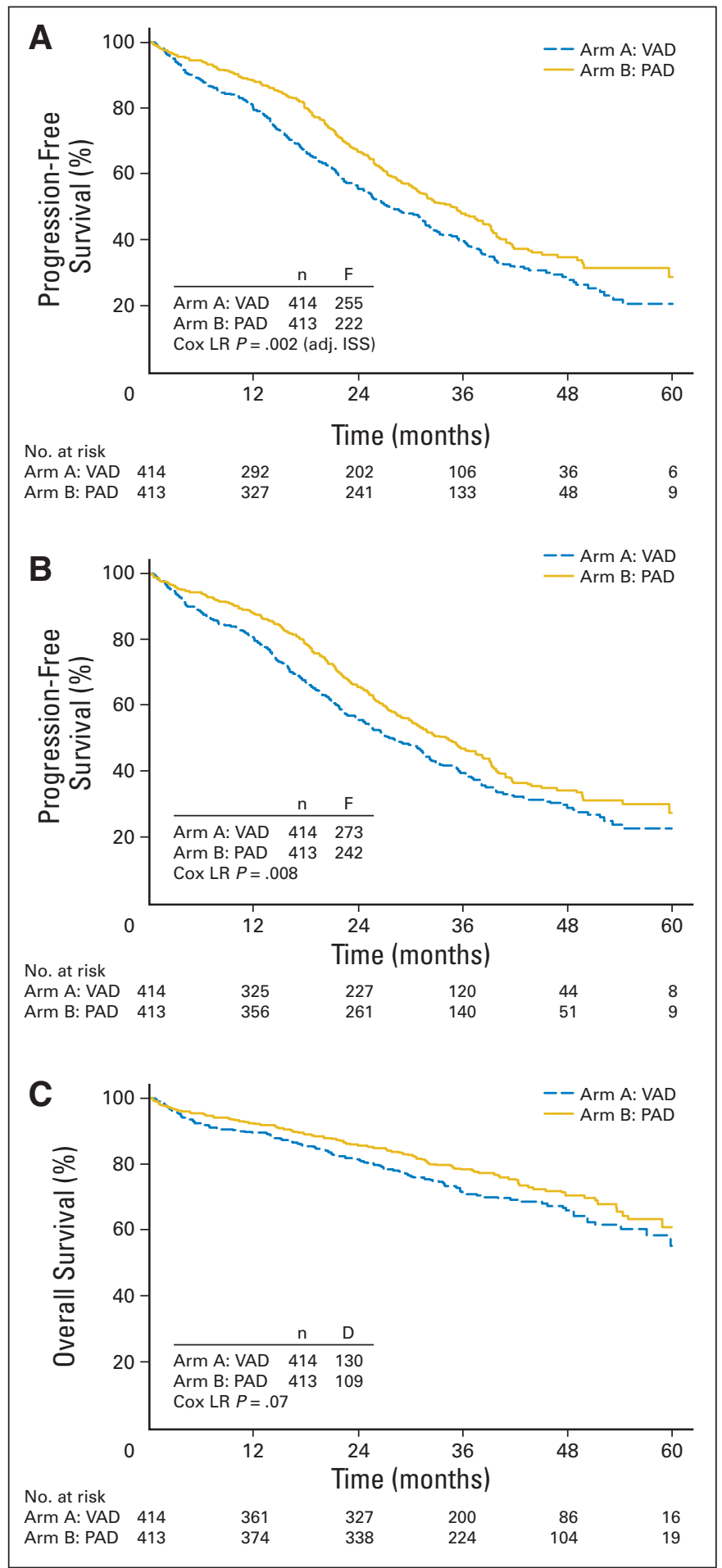

Fig 2. Kaplan-Meier survival curves among patients with multiple myeloma, according to randomly assigned treatment arm. (A) Progression-free survival (censored at allogeneic stem-cell transplantation); (B) progression-free survival (not censored at allogeneic stem-cell transplantation); (C) overall survival. adj. ISS, adjusted for International Staging System stage; Cox LR, Cox logistic regression; $D$, number of deaths; $F$, number of treatment failures (ie, progression, relapse, or death); PAD, bortezomib, doxorubicin, and dexamethasone; VAD, vincristine, doxorubicin, and dexamethasone. 


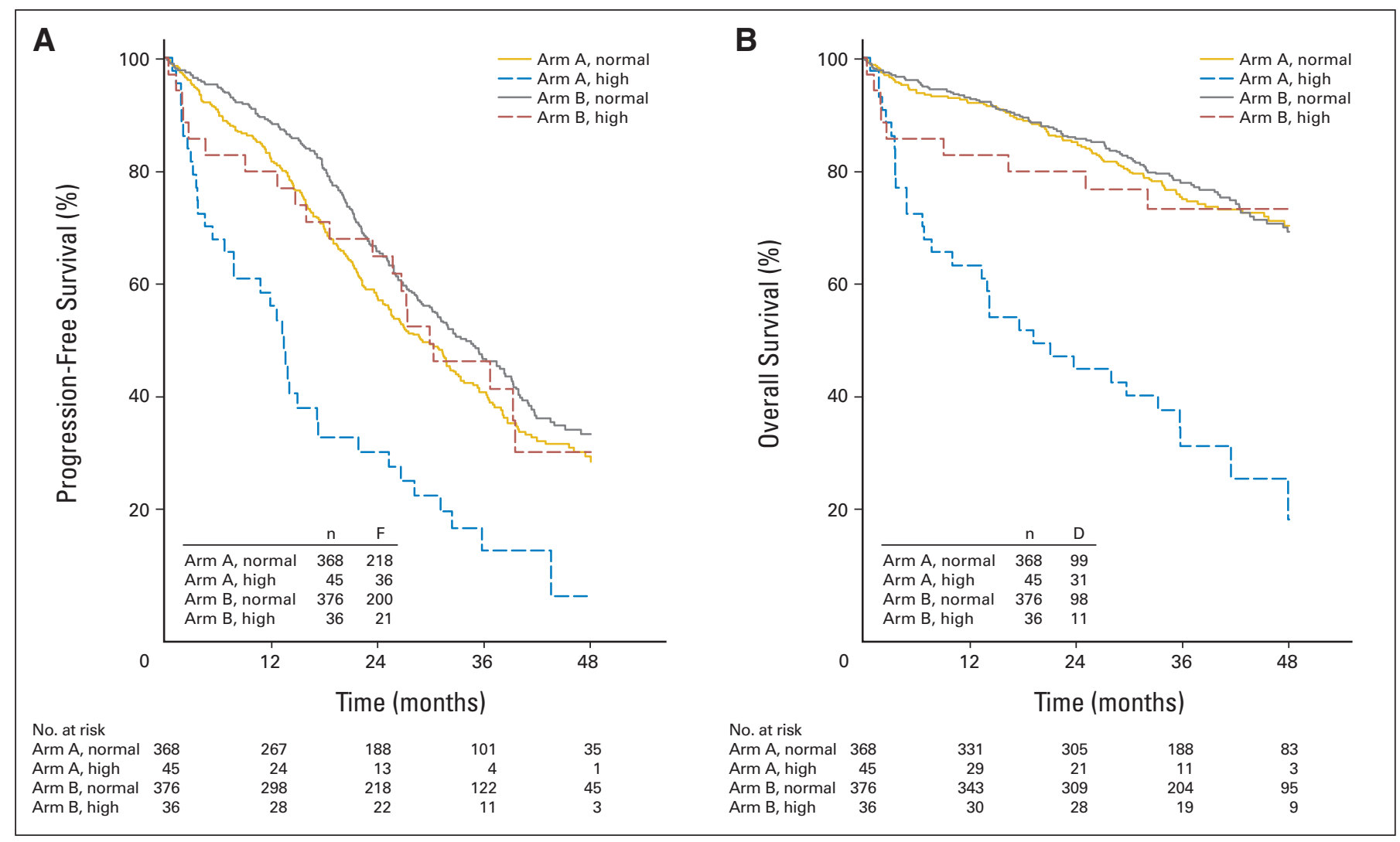

Fig 3. Kaplan-Meier survival curves of progression-free survival and overall survival according to treatment arm within subgroups according to creatinine level at

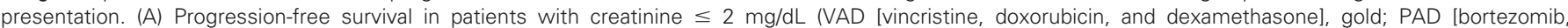

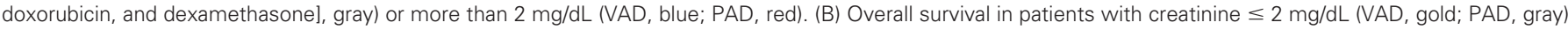
or more than $2 \mathrm{mg} / \mathrm{dL}$ (VAD, blue; PAD, red). D, number of deaths; F, number of treatment failures (ie, progression, relapse, or death).

and OS ( $21 v 54$ months; HR, 0.33; 95\% CI, 0.16 to $0.65 ; P<.001)$ dramatically improved with bortezomib compared with $\mathrm{VAD} /$ thalidomide (Fig 3). In patients with normal serum creatinine, PFS (median $31 v 35$ months; HR, 0.80; 95\% CI, 0.66 to $0.97 ; P=.02$ ) remained superior in the PAD arm, but OS was similar between the arms (59\% $v 62 \%$ at 5 years; $\mathrm{HR}, 0.94 ; 95 \% \mathrm{CI}, 0.71$ to $1.25 ; P=.94)$.

Subgroup analyses were also performed for FISH abnormalities, such as del(13q14), $t(4 ; 14)$, and del(17p13) (Table 1). In these analyses, patients with abnormal FISH results were compared with all patients without the abnormality. In patients with del(13q14), a negative impact on PFS was observed in both treatment arms (Fig $4 \mathrm{~A})$. OS in patients with this deletion was similar to the OS in patients with no del(13q14) in the PAD arm and significantly better than OS in the VAD arm (median OS, $49 v 59$ months; HR, $0.60 ; 95 \%$ CI, 0.42 to $0.87 ; P=.007$; Fig $4 \mathrm{~B})$. $\mathrm{t}(4 ; 14)$ was associated with worse PFS (HR, 1.76; 95\% CI, 1.32 to $2.36 ; P<.001$ ) and OS (HR, 2.13; 95\% CI, 1.45 to $3.15 ; P<.001$ ). Although PAD achieved better results in patients with $t(4 ; 14)$, this did not reach statistical significance (Figs 4C and 4D).

In patients with del(17p13), both PFS (median PFS, $12 v 22$ months; HR, 0.47; 95\% CI, 0.26 to $0.86 ; P=.01$; Fig $4 \mathrm{E}$ ) and OS (median OS, $24 v>54$ months; HR, 0.36 ; $95 \%$ CI, 0.18 to $0.74 ; P=$ .003; Fig $4 \mathrm{~F}$ ) were significantly better in the PAD arm. In patients without del(17p13), OS was identical in both treatment arms (HR, 0.96 ; $95 \%$ CI, 0.69 to $1.34 ; P=.81$ ). An analysis of all FISH abnormalities has been published separately. ${ }^{32}$
Because the double HDM/ASCT policy was statistically significant in the multivariate analysis for OS, it was decided to also analyze some of the outcomes for HOVON (single HDM/ASCT) and GMMG (double HDM/ASCT). In the HOVON patients, the $\mathrm{nCR} / \mathrm{CR}$ rate after maintenance was $29 \%$ in the VAD arm and $47 \%$ in the PAD arm (odds ratio, $2.21 ; 95 \% \mathrm{CI}, 1.49$ to $3.30 ; P<.001$ ). The median PFS was 24 months versus 32 months (HR, 0.70; 95\% CI, 0.55 to $0.91 ; P=.006)$. OS was $55 \%$ at 5 years in both arms (HR, $0.87 ; 95 \% \mathrm{CI}, 0.62$ to $1.20 ; P=.39$ ). In the GMMG patients, the $\mathrm{nCR} / \mathrm{CR}$ rate after maintenance was $39 \%$ in the VAD arm and $51 \%$ in the PAD arm (odds ratio, $1.58 ; 95 \% \mathrm{CI}, 1.06$ to $2.35 ; P=.03$ ). The median PFS was 31 months versus 36 months (HR, 0.80; 95\% CI, 0.62 to $1.04 ; P=.09)$. OS was $54 \%$ versus $70 \%$ at 5 years (HR, $0.69 ; 95 \%$ CI, 0.46 to $1.04 ; P=.07)$.

\section{DISCUSSION}

This randomized multicenter trial in patients with MM who were eligible for high-dose therapy demonstrates that bortezomib during induction and maintenance treatment results in a better response, quality of response, PFS, and OS. In this trial, no random assignment for maintenance therapy was performed; consequently, this cannot be independently assessed. Instead, we attempted to determine whether bortezomib before and after high-dose therapy might result in prolonged PFS. Maintenance treatment with bortezomib for 2 years was 

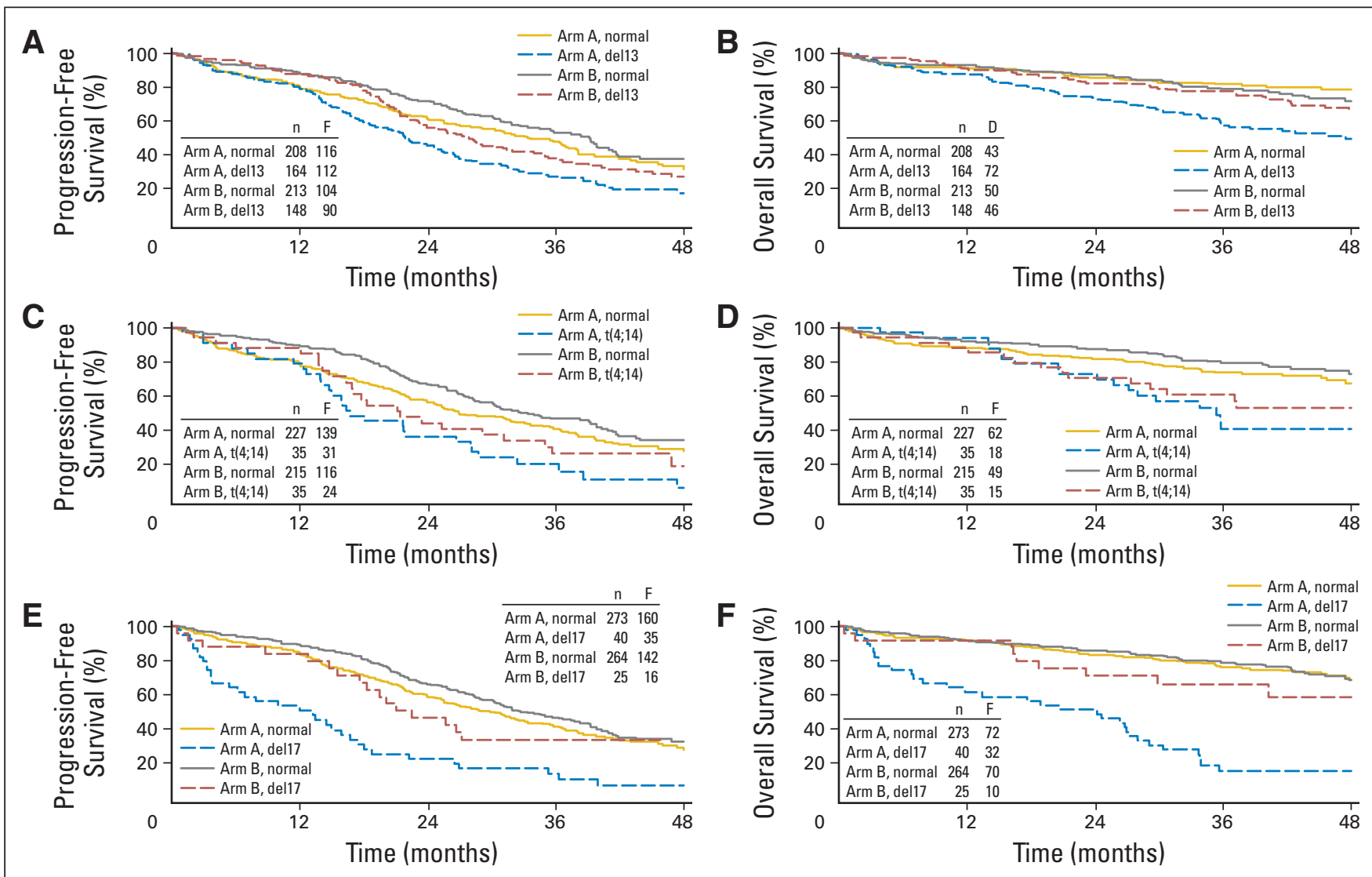

Fig 4. Kaplan-Meier survival curves of progression-free survival (PFS) and overall survival (OS) according to treatment arm within subgroups according to del(13/13q)

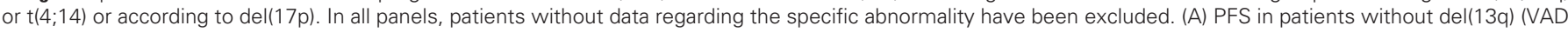

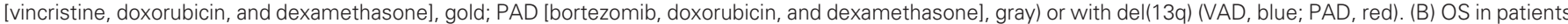

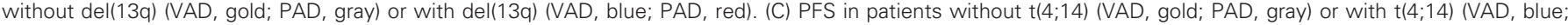

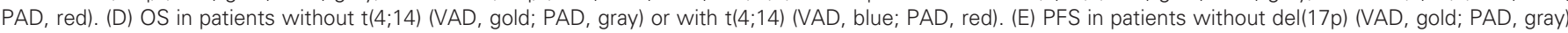

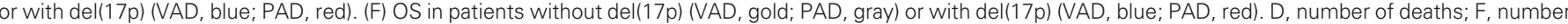
of treatment failures (ie, progression, relapse, or death).

much better tolerated than thalidomide maintenance, with fewer patients stopping their treatment prematurely. Bortezomib maintenance significantly improved the nCR plus CR rate from $31 \%$ to $49 \%$. A landmark analysis indicated that nCR plus CR at 12 months was associated with better PFS and OS. The subgroup analyses show that the superior outcome with bortezomib is predominantly accomplished in patients with high-risk disease, myeloma-related renal failure, and del(17p). There seemed to be less difference in PFS between the treatment arms in patients without the high-risk characteristics. In addition, OS was better in the GMMG group, which performed standard double HDM with ASCT in 69\% of patients in contrast to HOVON ( single HDM). Previous trials have not clearly demonstrated a survival benefit of double versus single HDM. ${ }^{33,34}$ Because the trial was not powered to compare single versus double HDM, the question remains open.

Other studies have explored induction treatment with bortezomib in two- or three-drug combinations such as bortezomib and dexamethasone (BD), BD with cyclophosphamide (VCD), BD with thalidomide (VTD), or BD with lenalidomide (VRD) in newly diagnosed patients. All observed a higher VGPR or CR rate and/or an improvement of PFS but not OS compared with standard treatment. ${ }^{13,35-38}$ The Intergroupe Francophone du Myélome (IFM 2005-01) trial $^{35}$ was not designed to evaluate OS. In the Gruppo Italiano Malattie Ematologiche dell'Adulto (GIMEMA) and University of Arkansas for Medical Sciences (UAMS) TT2 and TT3 trials, there was no difference in OS. ${ }^{25,36}$ In Total Therapy 3, bortezomib was given from induction through consolidation and maintenance, resulting in a 5-year OS of $72 \% .{ }^{39}$ Bortezomib consolidation after HDM was recently investigated..$^{25}$ Monotherapy of 20 injections over 21 weeks was well tolerated (mean total dose, $82 \%$ ), the rate of VGPR or better increased from $39 \%$ to $70 \%$, and median PFS increased from 20 months (VAD) to 27 months (PAD).

The Spanish PETHEMA group used VTD induction without consolidation, showing a post-ASCT CR rate of $46 \% .{ }^{40}$ In GIMEMA, VTD induction and consolidation after HDM resulted in an improved CR from 19\% after induction to $42 \%$ after second HDM and 49\% after consolidation. ${ }^{13}$ These results indicate that post-HDM consolidation with bortezomib may increase CR or VGPR. Maintenance treatment with bortezomib, as in this trial, may offer the same CR/ $\mathrm{nCR}$ and an improved PFS and OS.

Bortezomib-emergent peripheral neuropathy (BiPN) was the prevalent toxicity during induction, preventing a substantial number of patients from starting maintenance. In those who started maintenance, 5\% experienced BiPN grade 3 to 4 toxicity. More 
patients were unable to complete thalidomide maintenance treatment. Hence, the lower percentage of failures in the bortezomib arm may have contributed to the better PFS/OS in that group. Prolonged administration of bortezomib in the once every 2 weeks schedule seems feasible, and therefore it is important to prevent BiPN during induction, enabling patients to continue into maintenance. The tolerability of the two-weekly schedule is in line with the reported weekly schedule. ${ }^{4}$ In addition, subcutaneous administration may further improve tolerability. ${ }^{41}$ Recently, a significant prolongation of PFS and/or OS was demonstrated with lenalidomide maintenance after high-dose therapy. ${ }^{23,24}$ Future trials will address the optimal choice for maintenance treatment.

Our subgroup analyses revealed that bortezomib was superior for $\mathrm{CR} / \mathrm{nCR}, \mathrm{PFS}$, and $\mathrm{OS}$ in patients presenting with renal insufficiency, almost to the level of patients without organ failure. Although the safety and efficacy of bortezomib in renal failure has been observed in phase II studies, ${ }^{42-44}$ this trial prospectively defines the benefit of bortezomib in these high-risk patients.

The reported better outcome with bortezomib of patients with $t(4$; 14) was not confirmed. Although bortezomib treatment resulted in better PFS and OS, the outcome remained inferior compared with patients without $\mathrm{t}(4 ; 14)$. Bortezomib significantly improved PFS and OS in patients with del(13q14) and more importantly in del(17p13), identifying a potential effective treatment option in this high-risk group. In the recent IFM trial ${ }^{17}$ that used bortezomib plus dexamethasone for induction, no improvement of PFS was observed in patients with del(17p), indicating that induction with bortezomib may not be sufficient and that longer treatment may be required for better outcome. Because a plateau in PFS and OS was not observed, longer follow-up is warranted. In conclusion, bortezomib during induction and maintenance improves response, PFS, and OS in patients with MM.

\section{AUTHORS' DISCLOSURES OF POTENTIAL CONFLICTS OF INTEREST}

Although all authors completed the disclosure declaration, the following author(s) and/or an author's immediate family member(s) indicated a financial or other interest that is relevant to the subject matter under consideration in this article. Certain relationships marked with a " $U$ " are those for which no compensation was received; those relationships marked with a " $C$ " were compensated. For a detailed description of the disclosure categories, or for more information about ASCO's conflict of interest policy, please refer to the Author Disclosure Declaration and the Disclosures of Potential Conflicts of Interest section in Information for Contributors.
Employment or Leadership Position: Helgi van der Velde, Janssen Pharmaceuticals (C) Consultant or Advisory Role: Pieter Sonneveld, Celgene (C), Janssen Pharmaceuticals (C), Millennium Pharmaceuticals (C); Ingo G.H. Schmidt-Wolf, Janssen Pharmaceuticals (C); Hans Salwender, Janssen Pharmaceuticals (C); Sonja Zweegman, Janssen Pharmaceuticals (C); Katja C. Weisel, Celgene (C); Hartmut M. Goldschmidt, Celgene (C), Janssen Pharmaceuticals (C) Stock

Ownership: Helgi van der Velde, Johnson \& Johnson Honoraria: Pieter Sonneveld, Janssen Pharmaceuticals, Millennium Pharmaceuticals; Ingo G.H. Schmidt-Wolf, Janssen Pharmaceuticals; Hans Salwender, Celgene, Janssen Pharmaceuticals; Katja C. Weisel, Celgene, Janssen

Pharmaceuticals; Christof Scheid, Celgene, Janssen Pharmaceuticals, Novartis; Ulrich Duehrsen, Janssen-Cilag; Hartmut M. Goldschmidt, Celgene, Chugai Pharmaceutical, Janssen Pharmaceuticals, Novartis Research Funding: Pieter Sonneveld, Celgene, Janssen Pharmaceuticals; Katja C. Weisel, Celgene; Hartmut M. Goldschmidt, Celgene, Janssen Pharmaceuticals Expert Testimony: None Other Remuneration: Hans Salwender, Celgene, Janssen Pharmaceuticals

\section{AUTHOR CONTRIBUTIONS}

Conception and design: Pieter Sonneveld, Ingo G.H. Schmidt-Wolf, Sonja Zweegman, Edo Vellenga, Gerard M.J. Bos, Dirk Hose, Marinus van Marwijk-Kooy, Pierre W. Wijermans, Henk M. Lokhorst, Hartmut M. Goldschmidt

Financial support: Helgi van der Velde

Administrative support: Bronno van der Holt, Laila el Jarari, Uta Bertsch, Henk M. Lokhorst, Hartmut M. Goldschmidt

Provision of study materials or patients: Pieter Sonneveld, Ingo G.H. Schmidt-Wolf, Hans Salwender, Sonja Zweegman, Edo Vellenga, Igor W. Blau, Katja C. Weisel, Shulamiet Wittebol, Gerard M.J. Bos, Marian Stevens-Kroef, Christof Scheid, Michael Pfreundschuh, Dirk Hose, Helgi van der Velde, Reinier Raymakers, Martijn R. Schaafsma, Marie-Jose Kersten, Marinus van Marwijk-Kooy, Ulrich Duehrsen, Walter Lindemann, Pierre W. Wijermans, Henk M. Lokhorst, Hartmut M. Goldschmidt

Collection and assembly of data: Pieter Sonneveld, Ingo G.H.

Schmidt-Wolf, Laila el Jarari, Uta Bertsch, Hans Salwender, Sonja Zweegman, Edo Vellenga, Annemiek Broyl, Igor W. Blau, Katja C. Weisel, Shulamiet Wittebol, Gerard M.J. Bos, Marian Stevens-Kroef, Christof Scheid, Michael Pfreundschuh, Anna Jauch, Reinier Raymakers, Martijn R. Schaafsma, Marie-Jose Kersten, Marinus van Marwijk-Kooy, Ulrich Duehrsen, Walter Lindemann, Pierre W. Wijermans, Henk M. Lokhorst, Hartmut M. Goldschmidt

Data analysis and interpretation: Pieter Sonneveld, Ingo G.H.

Schmidt-Wolf, Bronno van der Holt, Laila el Jarari, Sonja Zweegman, Marian Stevens-Kroef, Christof Scheid, Dirk Hose, Helgi van der Velde, Pierre W. Wijermans, Henk M. Lokhorst, Hartmut M. Goldschmidt Manuscript writing: All authors

Final approval of manuscript: All authors

\section{REFERENCES}

1. Harousseau JL: Hematopoietic stem cell transplantation in multiple myeloma. J Natl Compr Canc Netw 7:961-970, 2009

2. Attal M, Harousseau JL, Stoppa AM, et al: A prospective, randomized trial of autologous bone marrow transplantation and chemotherapy in multiple myeloma: Intergroupe Français du Myélome. N Engl J Med 335:91-97, 1996

3. Child JA, Morgan GJ, Davies FE, et al: High-dose chemotherapy with hematopoietic stem-cell rescue for multiple myeloma. N Engl J Med 348:1875-1883, 2003

4. Palumbo A, Anderson K: Multiple myeloma. N Engl J Med 364:1046-1060, 2011
5. Segeren CM, Sonneveld $P$, van der Holt B, et al: Vincristine, doxorubicin and dexamethasone (VAD) administered as rapid intravenous infusion for first-line treatment in untreated multiple myeloma. Br J Haematol 105:127-130, 1999

6. Alexanian R, Barlogie B, Tucker S: VAD-based regimens as primary treatment for multiple myeloma. Am J Hematol 33:86-89, 1990

7. Richardson PG, Sonneveld P, Schuster MW, et al: Bortezomib or high-dose dexamethasone for relapsed multiple myeloma. N Engl J Med 352:2487-2498, 2005

8. Richardson PG, Barlogie B, Berenson J, et al: A phase 2 study of bortezomib in relapsed, refractory myeloma. N Engl J Med 348:2609-2617, 2003

9. Dimopoulos M, Spencer A, Attal M, et al: Lenalidomide plus dexamethasone for relapsed or refractory multiple myeloma. N Engl J Med 357: 2123-2132, 2007

10. Weber DM, Chen C, Niesvizky R, et al: Lenalidomide plus dexamethasone for relapsed multiple myeloma in North America. N Engl J Med 357:21332142, 2007

11. San Miguel JF, Schlag $R$, Khuageva NK, et al: Bortezomib plus melphalan and prednisone for initial treatment of multiple myeloma. $N$ Engl J Med 359:906-917, 2008

12. Harousseau JL, Attal M, Leleu $X$, et al: Bortezomib plus dexamethasone as induction treatment prior to autologous stem cell transplantation in patients with newly diagnosed multiple myeloma: Results of an IFM phase II study. Haematologica 91:1498-1505, 2006 
13. Cavo $M$, Tacchetti $P$, Patriarca $F$, et al: Bortezomib with thalidomide plus dexamethasone compared with thalidomide plus dexamethasone as induction therapy before, and consolidation therapy after, double autologous stem-cell transplantation in newly diagnosed multiple myeloma: A randomised phase 3 study. Lancet 376:2075-2085, 2010

14. Harousseau JL, Attal M, Avet-Loiseau H: The role of complete response in multiple myeloma. Blood 114:3139-3146, 2009

15. van de Velde HJ, Liu X, Chen G, et al: Complete response correlates with long-term survival and progression-free survival in high-dose therapy in multiple myeloma. Haematologica 92:1399-1406, 2007

16. Munshi NC, Anderson KC, Bergsagel PL, et al: Consensus recommendations for risk stratification in multiple myeloma: Report of the International Myeloma Workshop Consensus Panel 2. Blood 117: 4696-4700, 2011

17. Avet-Loiseau H, Leleu $X$, Roussel $M$, et al: Bortezomib plus dexamethasone induction improves outcome of patients with $t(4 ; 14)$ myeloma but not outcome of patients with del(17p). J Clin Oncol 28:4630-4634, 2010

18. Fonseca R, Bergsagel $P L$, Drach J, et al: International Myeloma Working Group molecular classification of multiple myeloma: Spotlight review. Leukemia 23:2210-2221, 2009

19. Palumbo A, Gay F, Falco $P$, et al: Bortezomib as induction before autologous transplantation, followed by lenalidomide as consolidation-maintenance in untreated multiple myeloma patients. J Clin Oncol 28:800-807, 2010

20. Lokhorst HM, van der Holt B, Zweegman S, et al: A randomized phase 3 study on the effect of thalidomide combined with adriamycin, dexamethasone, and highdose melphalan, followed by thalidomide maintenance in patients with multiple myeloma. Blood 115:1113-1120 2010

21. Morgan GJ, Gregory WM, Davies FE, et al: The role of maintenance thalidomide in multiple myeloma: MRC Myeloma IX results and metaanalysis. Blood 119:7-15, 2012

22. Attal M, Harousseau JL, Leyvraz S, et al: Maintenance therapy with thalidomide improves survival in patients with multiple myeloma. Blood 108:3289-3294, 2006

23. Attal M, Lauwers Cances $V$, Marit $G$, et al: Lenalidomide maintenance after stem-cell transplantation for multiple myeloma. N Engl J Med 366:1782-1791, 2012
24. McCarthy PL, Owzar K, Hofmeister CC, et al: Lenalidomide after stem-cell transplantation for multiple myeloma. N Engl J Med 366:1770-1781, 2012

25. Melqvist $U$, Gimsing $P$, Hjertner $O$, et al: Improved progression free survival with bortezomib consolidation after high dose melphalan; results of a randomized phase III trial. Haematologica 96:S31, 2011 (suppl)

26. Barlogie B, Anaissie $E$, van Rhee $F$, et al: Incorporating bortezomib into upfront treatment for multiple myeloma: Early results of Total Therapy 3. Br J Haematol 138:176-185, 2007

27. Oakervee HE, Popat R, Curry N, et al: PAD combination therapy (PS-341/bortezomib, doxorubicin and dexamethasone) for previously untreated patients with multiple myeloma. $\mathrm{Br} J$ Haematol 129:755-762, 2005

28. Pocock SJ: Allocation of patients to treatment in clinical trials. Biometrics 35:183-197, 1979

29. Neben $K$, Jauch $A$, Bertsch $U$, et al: Combining information regarding chromosomal aberrations $t(4 ; 14)$ and del(17p13) with the International Staging System classification allows stratification of myeloma patients undergoing autologous stem cell transplantation. Haematologica 95:1150-1157, 2010

30. Bladé J, Samson D, Reece D, et al: Criteria for evaluating disease response and progression in patients with multiple myeloma treated by high-dose therapy and haemopoietic stem cell transplantation: Myeloma Subcommittee of the EBMT-European Group for Blood and Marrow Transplant. $\mathrm{Br} J$ Haematol 102:1115-1123, 1998

31. Durie BG, Harousseau JL, Miguel JS, et al: International uniform response criteria for multiple myeloma. Leukemia 20:1467-1473, 2006

32. Neben $K$, Lokhorst HM, Jauch A, et al: Administration of bortezomib before and after autologous stem-cell transplantation improves outcome in multiple myeloma patients with deletion 17p. Blood 119:940-948, 2012

33. Attal M, Harousseau JL, Facon T, et al: Single versus double autologous stem-cell transplantation for multiple myeloma. N Engl J Med 349:2495-2502, 2003

34. Cavo M, Tosi P, Zamagni E, et al: Prospective, randomized study of single compared with double autologous stem-cell transplantation for multiple myeloma: Bologna 96 clinical study. J Clin Oncol 25: 2434-2441, 2007

35. Harousseau JL, Attal M, Avet-Loiseau H, et al: Bortezomib plus dexamethasone is superior to vincristine plus doxorubicin plus dexamethasone as induction treatment prior to autologous stem-cell transplantation in newly diagnosed multiple myeloma: Results of the IFM 2005-01 phase III trial. J Clin Oncol 28:4621-4629, 2012

36. Nair B, van Rhee F, Shaughnessy JD Jr, et al: Superior results of Total Therapy 3 (2003-33) in gene expression profiling-defined low-risk multiple myeloma confirmed in subsequent trial 2006-66 with VRD maintenance. Blood 115:4168-4173, 2010

37. Kropff M, Liebisch $P$, Knop S, et al: DSMM XI study: Dose definition for intravenous cyclophosphamide in combination with bortezomib/dexamethasone for remission induction in patients with newly diagnosed myeloma. Ann Hematol 88:1125-1130, 2009

38. Richardson PG, Weller E, Lonial $S$, et al: Lenalidomide, bortezomib, and dexamethasone combination therapy in patients with newly diagnosed multiple myeloma. Blood 116:679-686, 2010

39. van Rhee F, Szymonifka J, Anaissie E, et al: Total Therapy 3 for multiple myeloma: Prognostic implications of cumulative dosing and premature discontinuation of VTD maintenance components, bortezomib, thalidomide, and dexamethasone, relevant to all phases of therapy. Blood 116:1220-1227, 2010

40. Rosiñol L, Pérez-Simón JA, Sureda $A$, et al: A prospective PETHEMA study of tandem autologous transplantation versus autograft followed by reducedintensity conditioning allogeneic transplantation in newly diagnosed multiple myeloma. Blood 112:3591-3593, 2008

41. Moreau P, Pylypenko H, Grosicki $S$, et al: Subcutaneous versus intravenous administration of bortezomib in patients with relapsed multiple myeloma: A randomised, phase 3, non-inferiority study. Lancet Oncol 12:431-440, 2011

42. Ludwig H, Drach J, Graf H, et al: Reversal of acute renal failure by bortezomib-based chemotherapy in patients with multiple myeloma. Haematologica 92:1411-1414, 2007

43. Ludwig $H$, Adam Z, Hajek R, et al: Light chain-induced acute renal failure can be reversed by bortezomib-doxorubicin-dexamethasone in multiple myeloma: Results of a phase II study. J Clin Oncol 28:4635-4641, 2010

44. Dimopoulos MA, Terpos E, Chanan-Khan A, et al: Renal impairment in patients with multiple myeloma: A consensus statement on behalf of the International Myeloma Working Group. J Clin Oncol 28:4976-4984, 2010

\section{Affiliations}

Pieter Sonneveld and Annemiek Broyl, Erasmus Medical Center; Bronno van der Holt and Laila el Jarari, Erasmus Medical Center-Daniel den Hoed Cancer Center, Rotterdam; Sonja Zweegman, Vreij Universitet University Medical Center; Marie-Jose Kersten, Academic Medical Center, Amsterdam; Edo Vellenga, University Medical Center Groningen, Groningen; Shulamiet Wittebol, Meander Medical Center, Amersfoort; Gerard M.J. Bos, Maastricht University Medical Center, Maastricht; Marian Stevens-Kroef and Reinier Raymakers, University Medical Center Nijmegen, Nijmegen; Martijn R. Schaafsma, Medical Spectrum Twente, Enschede; Marinus van Marwijk-Kooy, Isala Clinics, Zwolle; Pierre W. Wijermans, Haga Hospital, the Hague; Henk M. Lokhorst, Utrecht Medical Center, Utrecht, the Netherlands; Ingo G.H. SchmidtWolf, University of Bonn, Bonn; Uta Bertsch, Dirk Hose, Anna Jauch, and Hartmut M. Goldschmidt, University Hospital of Heidelberg, Heidelberg; Hans Salwender, Asklepios Klinik Altona, Hamburg; Igor Wolfgang Blau, Charité Campus Benjamin Franklin, Berlin; Katja Christina Weisel, University of Tuebingen, Tuebingen; Christof Scheid, University Hospital of Cologne, Cologne; Michael Pfreundschuh, Saarland University Medical School, Homburg/Saar; Ulrich Duehrsen, University Hospital Essen, Essen; Walter Lindemann, Katholische Krankenhaus Hagen, Hagen, Germany; and Helgi van der Velde, Janssen Pharmaceuticals, Beerse, Belgium. 


\section{CORRECTIONS}

\section{Author Correction}

The June 10, 2012, article by Lynch et al, entitled, "Ipilimumab in Combination With Paclitaxel and Carboplatin As FirstLine Treatment in Stage IIIB/IV Non-Small-Cell Lung Cancer: Results From a Randomized, Double-Blind, Multicenter Phase II Study" (J Clin Oncol 30:2046-2054, 2012) contained an error.

In the Results section, under Efficacy, the last sentence of the second paragraph was given as: "Rates of OS for phased ipilimumab, concurrent ipilimumab, and control group were
$42 \%, 50 \%$, and $39 \%$, respectively, at 1 year and $16 \%, 18 \%$, and $18 \%$, respectively, at 2 years."

While it should have been: "Rates of OS for concurrent ipilimumab, phased ipilimumab, and control group were $42 \%, 50 \%$, and $39 \%$, respectively, at 1 year and $16 \%, 18 \%$, and $18 \%$, respectively, at 2 years."

The authors apologize for the mistake.

DOI: 10.1200/JCO.2012.46.6904; published May 20, 2012

\section{Journal Correction}

The August 20, 2012, article by Sonneveld et al, entitled, "Bortezomib Induction and Maintenance Treatment in Patients With Newly Diagnosed Multiple Myeloma: Results of the Randomized Phase III HOVON-65/GMMG-HD4 Trial" (J Clin Oncol 30:2946-2955, 2012), contained errors.

In the Results section, under PFS and OS, the fifth sentence of the second paragraph referenced Figure $3 \mathrm{~A}$, whereas it should have been Appendix Figure A1A, as follows: "An analysis of PFS calculated from the time of last HDM $(n=645)$ showed a significant difference in favor of the PAD arm, with a median of 26 months versus 31 months (Appendix Fig A1A, online only)."

Also under PFS and OS, in the last sentence of the second paragraph, Figures $3 \mathrm{~B}$ and $\mathrm{C}$ were referenced, whereas it should have been Appendix Figures A1B and C, as follows: "In a landmark analysis starting at 12 months after random assignment for 585 patients (283, VAD; 302, PAD) who had received $\mathrm{HDM} / \mathrm{ASCT}$ and were still without progression, $\mathrm{PFS}(P=.04$; Appendix Fig A1B $)$ and $O S(P=.05$; Appendix Fig A1C) were improved in the PAD arm."

In the Results section, under Secondary Analyses, the second-to-last sentence of the first paragraph referenced Figure 4, whereas it should have been Figure 3, as follows: "In these patients, both median PFS ( $13 v 30$ months; HR, 0.45; 95\% CI,
0.26 to $0.78 ; P=.004)$ and OS ( $21 v 54$ months; HR, 0.33 ; $95 \%$ CI, 0.16 to $0.65 ; P<.001)$ dramatically improved with bortezomib compared with VAD/thalidomide (Fig 3)."

Also under Secondary Analyses, in the second and third paragraphs, Appendix Figures A1A-F were referenced, whereas it should have been Figures 4A-F, as follows: "In patients with del(13q14), a negative impact on PFS was observed in both treatment arms (Fig 4A). OS in patients with this deletion was similar to the OS in patients with no del(13q14) in the PAD arm and significantly better than OS in the VAD arm (median OS, $49 v 59$ months; HR, 0.60; 95\% CI, 0.42 to $0.87 ; P=.007$; Fig 4B). $\mathrm{t}(4 ; 14)$ was associated with worse PFS (HR, 1.76; 95\% CI, 1.32 to $2.36 ; P<.001$ ) and OS (HR, 2.13; 95\% CI, 1.45 to 3.15; $P<.001)$. Although PAD achieved better results in patients with $\mathrm{t}(4 ; 14)$, this did not reach statistical significance (Figs $4 \mathrm{C}$ and $4 \mathrm{D})$. "In patients with del(17p13), both PFS (median PFS, $12 v 22$ months; HR, 0.47 ; $95 \%$ CI, 0.26 to 0.86 ; $P=.01$; Fig 4E) and OS (median OS, $24 v>54$ months; HR, 0.36; 95\% CI, 0.18 to $0.74 ; P=.003 ; \mathrm{Fig} 4 \mathrm{~F}$ ) were significantly better in the PAD arm. In patients without del(17p13), OS was identical in both treatment arms (HR, $0.96 ; 95 \% \mathrm{CI}, 0.69$ to $1.34 ; P=.81$ ).”

Journal of Clinical Oncology apologizes for the mistakes.

DOI: 10.1200/JCO.2012.46.6912; published May 20, 2012 